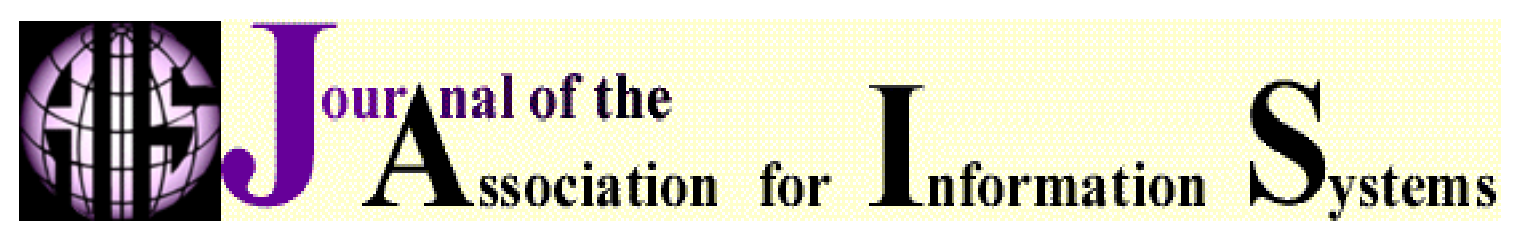

RESEARCH ARTICLE

\title{
Collective Action and Knowledge Contribution in Electronic Networks of Practice*
}

\author{
Molly McLure Wasko \\ Department of Management Information Systems \\ Florida State University \\ mwasko@cob.fsu.edu \\ Samer Faraj \\ Department of Decision and Information Technologies \\ R. H. Smith School of Business \\ University of Maryland \\ sfaraj@rhsmith.umd.edu \\ Robin Teigland \\ Department of Marketing and Strategy \\ Stockholm School of Economics \\ robin.teigland@hhs.se
}

\begin{abstract}
Although there has been a significant increase in networked communication and a growing interest in virtual organizing, to date researchers have yet to establish consistent terminology and have paid little attention to how specific characteristics of the electronic network influence social dynamics such as knowledge contribution. To address this gap, we develop a theoretical model and a set of propositions that explain knowledge contribution in voluntary, computer-mediated, very large and open networks focused on knowledge exchange around a specific practice. We base our model on theories of social networks and collective action to explain how a social network of volunteers sustains productive exchanges between individuals, such as the exchange of knowledge. We utilize the concept of a network of practice to illustrate how the macrostructural properties of the communication media, network size, access to the network, and mode of participation affect network dynamics and knowledge contribution. We then develop a model and a set of propositions to suggest that knowledge contribution within an electronic network of practice is dependent upon 1) the
\end{abstract}

\footnotetext{
${ }^{*}$ Robert Zmud was the accepting senior editor for this paper. Arun Rai and Manju Ahuja were reviewers for this paper.
} 
macrostructural properties of the network, 2) the structure of ties that create the network, 3) the relational quality of ties that develop between individuals and the network as a whole, 4) the use of social controls, and 5) the distribution of individual motivations and resources in the network. We further predict that knowledge contribution influences the distribution of individual motivations and resources, as well as serves to create and recreate network structure over time. We conclude with a discussion of the implications of our theory for current and future research.

Keywords: Network of practice, online communities, network governance, social networks, collective action, public goods

\section{Introduction}

The concept of a community of practice is emerging as an essential building block of the knowledge economy. Lave and Wenger (1991) describe a community of practice as an open activity system where individuals working on similar problems self-organize to help each other and share perspectives around a common practice. These communities support the exchange of ideas between members, resulting in learning and innovation within the community (Brown and Duguid, 1991; Wenger, 1998). For individuals engaged in complex knowledge tasks, communities of practice are needed because the knowledge necessary to perform effective work cannot be exclusively based on abstract, codified, and easily accessed bodies of information. Rather, knowledge, or more precisely, knowing, is a collective activity embodied in situated practice (Lave and Wenger, 1991).

Recent advances in information and communication technologies have enabled the creation of computer-supported social networks similar to communities of practice, where individuals are able to discuss and debate issues electronically. Through these electronic networks, individuals connect with others by exchanging electronic messages using basic Internet technologies. Participation within these electronic networks allows geographically dispersed individuals to gain access to new information, share expertise, and discuss ideas that are often not available locally or through their social networks of friends, contacts, and colleagues. Building upon the work of Brown and Duguid (2000), we refer to these computer supported networks as "electronic networks of practice."

With the evolution of new technology-enabled organizational forms, theoretical development is needed to address how participation and the contribution of knowledge is sustained in electronic networks of practice (Butler, 2001; Fulk et al.,1996), since there exist significant differences between electronic and face to face interactions (Hinds and Kiesler, 2002). For instance, an important characteristic of electronic networks of practice is that the collective knowledge generated by network members exhibits aspects of a public good. Individual consumption of this repository of collective knowledge is non-rival (i.e., consumption by one individual does not limit the consumption by another or diminish the value of the knowledge), and nonexcludable (i.e., the open nature of the network makes the resource accessible to all). Therefore, the knowledge generated in these electronic networks is an archetypal public good (Samuelson, 1954). However, as with the production of any public good by a collective, the ability of individuals to free-ride on the efforts of others without contributing in return poses a major threat to the development and sustainability of electronic networks of practice. Free-riding is an individually rational behavior that results in collective 
irrationality, since if everyone were to free-ride on the efforts of others, the public good would never be created in the first place. Thus, the key factor underlying the success and sustainability of these electronic networks is the propensity of individuals to voluntarily participate and provide their valuable knowledge and insights to others, even though there are no assurances that anyone will reciprocate the favor (Kollock and Smith, 1996; Rheingold, 1993; Wasko and Faraj, 2000). The important question this paper investigates is: in the face of self-interest and the ability to free-ride, how do electronic networks of practice sustain themselves by promoting voluntary contributions of knowledge?

The goal of this paper is to develop a theoretical framework and a set of propositions that focuses specifically on the dynamics underlying knowledge contribution in electronic networks of practice at the network level. We base our model on theories of social networks (Garton et al., 1999; Granovetter, 1973; Jones et al., 1997) and collective action (Hardin, 1982; Oliver et al., 1985; Olson, 1965). Both provide insights into why individuals voluntarily create and maintain public goods without the use of formal contracts or hierarchical controls. To do so, we introduce a social network perspective of knowledge exchange, focusing on the concepts of networks of practice, communities of practice, and electronic networks of practice to describe how the macrostructural properties of networks are relevant for understanding knowledge exchange. Based on the identified properties, we develop propositions to explain knowledge contribution in electronic networks of practice. By doing so, we offer a network-level explanation for why individuals invest their valuable time and energy to provide useful advice to strangers when they could just as easily free-ride on the efforts of others.

\section{A Social Network Perspective of Knowledge Exchange}

In this section, we discuss knowledge exchange from a social network perspective. In contrast to theories that examine individuals based on their attributes, such as gender, age, education or occupation, social network perspectives focus on how the relations between individuals influence interactions and outcomes. Below, we describe the attributes of social relations and how they are relevant for understanding knowledge exchange, and we limit the focus of our theoretical development to networks that are emergent and in which participation is voluntary. We then introduce the concept of a network of practice as a general term for describing social networks focused on the voluntary exchange of practice-related knowledge. This section concludes with a discussion of how the macrostructural properties of the network of practice, such as size, influence the pattern of relationships that develop within the network.

\section{Overview of social networks}

The concept of a "network" is broad and can be applied to a variety of phenomena where the focus is ascribing a set of relations to an identified set of entities. We focus on the relations that develop between individuals, although social networks may also emerge from the relations between groups, organizations, or artifacts, or a combination of these entities. Social network perspectives focus on the patterns and implications of the relations within a collective, suggesting that individuals and their actions are interdependent, rather than autonomous occurrences. One stream of social network research focuses on the personal network of one focal individual, referred to as an egocentered network. For instance, an ego-centered network may be examined to 
determine how an individual's set of relations or position in a network influences his or her access to resources. Another stream of social network research focuses on the examination of the network as a whole. For instance, analysis at the network level would reveal whether the pattern of relations within the network influences the ability of the network to engage in collective action. Consistent with this latter approach, we focus on theory development at the network level of analysis.

Social network dynamics are dependent upon both macrostructural and microstructural properties of the network (Granovetter, 1985). The macrostructural properties are exogenous variables that are related to the environmental conditions under which the network is created and sustained and that influence network dynamics. The microstructural properties consist of the individuals and relations between them that develop within the boundary of the network. At the microstructural level, social network analysis focuses on how relations, referred to as ties, relate to outcomes, such as how to explain the behaviors of network members or what effects these networks have on individuals and organizations. These ties vary in content, direction, and relational strength, all of which influence the dynamics of the network (Garton et al., 1999). The content of ties refers to the resources exchanged, such as information, money, advice, or kinship. The direction of ties indicates the giver of the resource and the receiver, although ties in some networks are undirected, such as kinship. The relational strength of ties pertains to the quality of the tie. For instance, the relational strength of ties indicates the amount of energy, emotional intensity, intimacy, commitment, and trust connecting the individuals.

Aggregating ties to the network level, the content of the ties indicates the subset of individuals to be included in the network and the boundary of the network. The direction of ties creates the network structure, indicating the network's overall pattern of ties and their resource flows. The relational strength of ties describes the quality of the relations in the network, indicating the degree to which individuals in the network are concerned about others' needs and goals.

In general, social network theories suggest that the structure of ties in the network influences their relational strength, which in turn influences the behavior of actors in the network. This general theory of social networks, that the structure of ties influences the relational strength of ties, which in turn affects how individuals act in the network, serves as the basis for the theoretical development undertaken in this paper.

\section{Macrostructural properties of networks of practice}

In order to develop a theory of knowledge contribution in electronic networks of practice, it is essential to first discuss the different properties of social networks and how these properties influence knowledge exchange. These properties result from macrostructural circumstances that lead networks to display the tie structure and relational strength they have (Granovetter, 1985). In this sense, we do not begin our theorizing by taking the network structure as given. Rather, we first account for the macrostructural properties of the network that influence tie structure, relational strength, and how electronic networks of practice emerge and persist.

To identify the relevant macrostructural properties along which networks may vary, we limit our focus to networks where the content of ties is knowledge. We begin by describing the concept of a "network of practice" (Brown and Duguid, 2000), and then 
comparing two types of networks of practice, communities of practice, and electronic networks of practice. The purpose of this comparison is to focus attention on how different macrostructural properties of the network influence network dynamics and knowledge contribution. This comparison provides the basis for the development of our theoretical model, and provides a basis for the comparison of different network structures to improve our understanding of research findings across settings.

Recently, the concept of "networks of practice" (Brown and Duguid, 2000, 2001) has emerged as a means to describe informal, emergent social networks that facilitate learning and knowledge sharing between individuals conducting practice-related tasks. In contrast to the use of formal controls to support knowledge exchange, such as contractual obligation, organizational hierarchies, monetary incentives, or mandated rules, networks of practice promote knowledge flows along lines of practice through informal social networks. Brown \& Duguid extend Lave \& Wenger's (1991) original framing of communities of practice to communities that emerge within organizations by defining this type of network of practice as a "relatively tight-knit groups of people who know each other and work together directly...typically face-to-face communities that continually negotiate with, communicate with, and coordinate with each other directly in the course of their work" (Brown and Duguid, 2000, pg. 143). They further propose that communities of practice are a localized and specialized subset of networks of practice, which typically consist of weaker ties linking individuals engaged in a shared practice, but who may never get to know one another or meet face-to-face. In networks of practice, individuals generally coordinate through third-party organizations, such as professional associations, or by indirect means, such as newsletters, websites, or bulletin boards (Brown and Duguid, 2000). We extend this work by viewing all networks of practice as consisting of a variety of macrostructural properties as exhibited in Table 1 , and we compare and contrast communities of practice with electronic networks of practice to illustrate these properties.

The first macrostructural property of formal control distinguishes a network of practice from other network forms. In networks of practice, there are no formal controls dictating interactions. The network is emergent and based upon the voluntary participation of individuals rather than mandated or controlled through contractual obligations or formal hierarchical authority, e.g., project team membership (Brown and Duguid, 2000, 2001). For example, in electronic networks of practice, individuals determine themselves whether and how often they want to participate with options ranging from passive observation (also known as "lurking") to active participation consisting of posting questions, replies, general comments, or a mixture of these.

The remaining macrostructural properties are dimensions along which different types of networks of practice may vary. The second macrostructural property is the primary media channel used for communication between network participants (e.g., face-to-face interactions), remote computer-mediated channels (such as newsletters or discussion boards), or a combination of these techniques. The communication media is important for understanding networks of practice, for this is the channel through which the resource of knowledge is exchanged. In electronic networks of practice, the primary communication channel of asynchronous computer-mediated communication has a profound influence on how knowledge is actually shared and exchanged (Daft and Lengel, 1986). For instance, in many electronic networks of practice the messages and their contents are available to all participants and sometimes archived for future reference, regardless of an individual's participation in the original exchange. This 
visibility provides network members with complete information about the conduct of other network members, and sharply contrasts with the ephemeral, typically private conversations between a limited number of individuals that occur in face-to-face communication.

The third macrostructural property is network size. As a network grows in its number of members, the dynamics change such that it becomes more difficult to sustain ties based on personal acquaintance and familiarity. In face-to-face communications, the requirements of co-presence and turn taking limit the size of the network. In contrast, the technology supporting electronic networks of practice removes physical restrictions on the number of participants, the quantity of messages, and even the size of the messages exchanged. This enables the development of very large networks consisting of hundreds to thousands of individuals.

The fourth macrostructural property is the extent to which access to the network is restricted. We focus on electronic networks of practice where participation is open to anyone with an interest in the practice. As long as an individual has access to the technology, participation is openly available regardless of physical location, demographics, organizational affiliation, social position, or personal expertise. Thus, electronic networks of practice may have thousands of members who are typically strangers coming from a wide variety of organizations across the globe. This openness sharply contrasts with the often restricted access to communities of practice. For example, if individuals are not co-located within the same organization or do not have opportunities to meet like-minded others, then it may be difficult to access relevant communities of practice.

The fifth macrostructural property is the extent to which individual participation is individually determined rather than jointly determined. Participation in electronic networks of practice is individually determined in that the individual determines the type and level of participation. Knowledge seekers have no control over who responds to their questions or the quality of the responses. In turn, knowledge contributors have no assurances that seekers will understand the answer provided or be willing to reciprocate the favor. In contrast, research on communities of practice has found that participation is jointly determined (Wenger, 1998). For example, although an individual may have access to a local community of practice, he or she may still be unable to become a legitimate peripheral participant due to tightly knit relationships between specific individuals within the community of practice (Wenger, 1998). Community of practice participation is also jointly determined due to the dyadic nature of community interaction. In communities of practice, individuals generally approach specific others for help. Thus, although there may be an individual who would like to contribute knowledge to the community, he or she may not have the opportunity if no other community of practice member approaches the individual.

We summarize the macrostructural properties relevant for understanding knowledge exchange in networks of practice in Table 1. It is important to note that these properties are dimensions along which networks of practice may vary and not dichotomous variables. We take the two extremes of these dimensions to compare and contrast communities of practice with electronic networks of practice to illustrate how these properties are relevant. The macrostructural properties of networks should be taken into account when comparing results across settings, noting that the structure and relational strength of ties in the network may change, as well as the dynamics underlying 
knowledge exchange. For instance, prior research consistently finds that knowledge exchange occurs in networks characterized by physical proximity (Allen, 1977; Kraut et al., 1990), demographic similarity (Pelled, 1996), status similarity (Cohen and Zhou, 1991), and a history of prior relationship (Krackhardt, 1992) because these conditions create networks where the structure of the ties is dense and reciprocal and the relational strength of the ties is high (Krackhardt, 1992).

\begin{tabular}{|c|c|c|}
\hline Table 1. Macrostructural Properties of Networks of Practice \\
\hline Macrostructural Property & Communities of Practice & $\begin{array}{c}\text { Electronic Networks of } \\
\text { Practice }\end{array}$ \\
\hline Network control & $\begin{array}{c}\text { No formal control, } \\
\text { voluntary }\end{array}$ & $\begin{array}{c}\text { No formal control, } \\
\text { voluntary }\end{array}$ \\
\hline Communication channel & Face to face & $\begin{array}{c}\text { Text-based computer- } \\
\text { mediated, e.g., listservs, } \\
\text { discussion boards }\end{array}$ \\
\hline Network size & Small & Large \\
\hline Access & $\begin{array}{c}\text { Restricted, locally } \\
\text { bounded, limited to co- } \\
\text { location }\end{array}$ & $\begin{array}{c}\text { Open, no limitations other } \\
\text { than access to technology }\end{array}$ \\
\hline Participation & Jointly determined & Individually determined \\
\hline
\end{tabular}

However, we know much less about knowledge exchange in networks of practice that display the properties characterizing electronic networks of practice. In the balance of this paper, we focus on electronic networks of practice where all interactions are emergent, voluntary, and occur through computer-mediated communication. In addition, the network is very large (hundreds to thousands of participants), membership is open to anyone with an interest in the shared practice, and participation is individually determined. These macrostructural properties are the starting point of our theoretical model and denote the boundary conditions of our theory.

\section{Theoretical Model and Propositions}

Our theoretical model is based on the premise that knowledge exchange in electronic networks of practice is sustained by both individual and network influences and that the network's structure of ties affects the relational strength of ties. We focus on knowledge contribution, which we view as occurring through the exchange of messages that add value to the network and create a public good of collective knowledge. While this general network theory can be applied to any network structure, we focus on developing a model of propositions specific to the baseline case of electronic networks of practice described above.

To summarize, we predict that the macrostructural properties lead to knowledge-based ties, which create a network structure characterized by generalized exchange. Networks 
supported through generalized exchange are sustained by the creation of strong relational ties between individuals and the network as a whole. In turn, networks where the relational strength of ties is high will have members concerned about the importance of social controls and are more likely to add value to the network by contributing knowledge. We also predict that knowledge contribution will be influenced by the distribution of individual resources and motivations within the network. The value created through knowledge contribution then feeds back to influence the level of individual resources and motivations, and serves to recreate the network structure over time. Figure 1 provides an overview of the theoretical model, and we develop specific propositions in the next section.

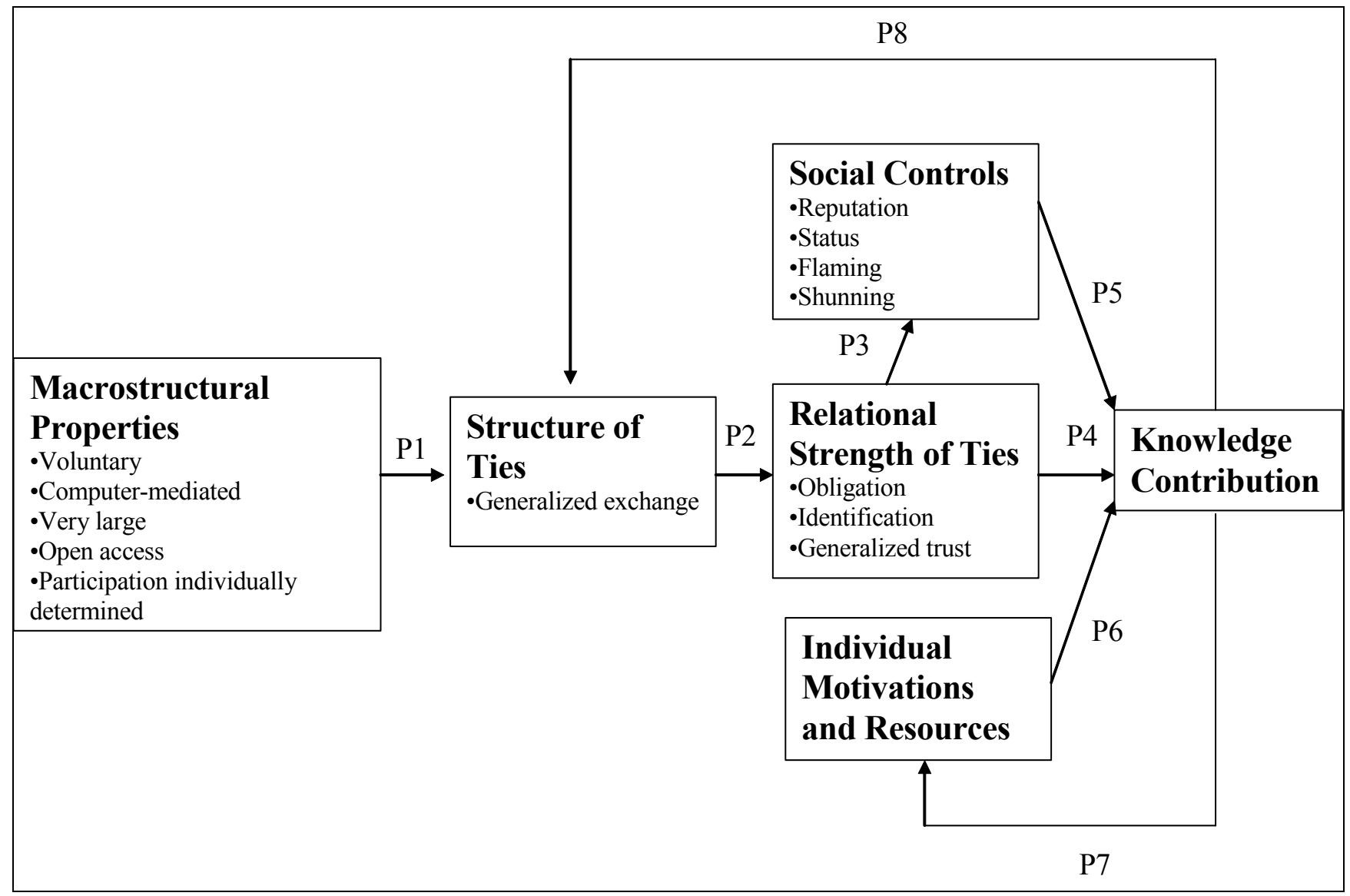

Figure 1 Knowledge Contribution in Electronic Networks of Practice

\section{Knowledge contribution in electronic networks of practice}

We are interested in describing how electronic networks of practice sustain the collective action of knowledge contribution. We make the basic assumptions that knowledge contribution is the primary source of value creation in these networks and that individuals are more likely to continue participating in an electronic network of practice when they perceive that value has been created. Since interactions are visible in electronic networks of practice, it is possible to investigate knowledge contribution and value creation by studying the pattern of message exchanges. We view this interaction as critical to the development and sustainability of the network because without interactions, there is no network structure. For example, if no one responds to posted 
questions, then no knowledge is contributed and little value is generated to encourage continued participation. If individuals simply post content, such as announcements, what evolves is more akin to a static website for content dissemination rather than an active network of mutual engagement and knowledge contribution focused on practice. We view knowledge contribution as occurring when individuals contribute useful, valuable, practice-related knowledge that facilitates the engagement of others in the practice.

\section{Macrostructural properties and the structure of ties in electronic networks of practice}

We posit that the macrostructural properties of the network will influence the structure of ties that develops in electronic networks of practice. The structure of ties in the network represents the extent to which a "dyad's mutual contacts are connected to one another" and is a function of how many individuals interact, expectations about future interactions, and the extent to which individuals share knowledge about these interactions (Granovetter, 1992, pg. 35). While prior research has argued that the structure of ties is important for sustaining collective action, exactly how and why is not well established (Marwell and Oliver, 1988). Early research suggested that when networks are dense, consisting of direct ties between all members, it is relatively easier to coordinate and sustain voluntary actions (Coleman, 1990). This is especially relevant when successful collective action requires the equal efforts of all network members to create and maintain the public good.

However, prior research also suggests that collective action does not require networks that are characterized by dense, reciprocal ties but can also occur in weak tie networks characterized by generalized exchange (Fulk et al., 1996). Generalized exchange occurs when one's giving is not reciprocated by the recipient, but by a third party (Ekeh, 1974). For example, individual $A$ helps individual $B$, but when individual $B$ asks for help, an unspecified individual $\mathrm{C}$ responds. In contrast to dyadic exchange characterized by direct reciprocity and accountability, generalized exchange is based on indirect reciprocation and interest-based contribution.

We predict that the structure of ties in electronic networks of practice will be characterized by generalized exchange. One reason for this prediction is that the posting and visibility of messages to all members in electronic networks of practice eliminate the need for people to know one another personally in order to access knowledge, which increases the chances of connecting with individuals who are willing and able to help. The tie connecting seekers and responders is based on knowledge, rather than personal familiarity or physical location. Another reason is that the knowledge in an electronic network of practice is distributed, meaning that no one individual can possibly possess all of the knowledge and answers. Seekers cannot predict potential knowledge sources, nor can contributors know beforehand what knowledge is most likely to benefit certain seekers. A third reason for the development of generalized exchange is that individual $A$ may not have the requisite knowledge or motivation to answer B's request, while $C$ may be able to easily formulate an effective answer. Therefore, we predict that the macrostructural properties of the network lead to ties that are based on knowledge, rather than personal acquaintance, and since this knowledge is distributed across the network, the structure of ties will resemble generalized exchange. This leads to the first proposition: 
Proposition 1: For emergent voluntary networks, the more interactions are predominately computer-mediated, the larger the size, the more access is unrestricted, and the more participation is individually determined, the greater the likelihood that the structure of ties will be characterized by generalized exchange.

\section{The structure of ties and the relational strength of ties in electronic networks of practice}

The relational strength of ties in a network refers to the nature and the quality of relations between the network's members (Nahapiet and Ghoshal, 1998). The structure of ties provides the foundation for the development of the relational strength of the ties, since network structures determine the spread of information about network members and their interactions. The relational strength of ties is important to understand since it influences the development of common understandings and norms (Friedkin, 1982), which in turn influence cooperative behaviors and collective action among the network's members (Granovetter, 1992; Jones et al., 1997). Collective action may be easier to achieve in networks where the ties are characterized by a high degree of goodwill, collective bonds, and expectations of pro-social behavior (Coleman, 1990; Putnam, 2000). Other attributes characterizing the relational strength of ties include trust (McAllister, 1995; Nahapiet and Ghoshal, 1998; Ring and Van de Ven, 1994), obligation to and identification with the collective (Nahapiet and Ghoshal, 1998), affiliation (Leana and Van Buren, 1999), commitment (Mowday et al., 1979), and organizational citizenship (Organ, 1988).

Prior research indicates that network structures characterized by dense, reciprocal ties are likely to create strong, relational ties between individuals (Jones et al.,1997; Krackhardt, 1992). This is because when individuals in a network know one other, dyadic exchanges result in expectations of future reciprocity and direct returns between individuals (Blau, 1964). However, in electronic networks of practice where the network structure is characterized by generalized exchange, ties are based on the distribution of knowledge rather than on personal acquaintance. This results in ties where seekers and responders are typically strangers and there are no assurances or expectations that help will be directly reciprocated, in sharp contrast to the direct, reciprocal ties that develop through face-to-face interactions and personal acquaintance. Therefore, we predict that the relevant ties providing relational strength within electronic networks of practice are not the ties between individuals within the network. Rather, the relevant ties are those that develop between each individual and the network as a whole.

These ties are characterized by the strength of an individual's relationship to the entire network (Leana and Van Buren, 1999) and are a collective good that benefits network members regardless of personal acquaintance (Nahapiet and Ghoshal, 1998). For example, prior research suggests that networks characterized by generalized exchange are sustained by generalized trust, solidarity, and other higher order concepts such as citizenship among active network members (Ekeh, 1974). These network-level ties are also likely to include a strong identification with the network (Kramer et al., 1996; Lewicki and Bunker, 1996), and a perceived obligation to the network (Bourdieu, 1977; Coleman, 1990). Thus, we predict the following relationship:

Proposition 2: The more the structure of ties in the network is characterized by generalized exchange, the greater the likelihood that the relational strength of the ties is determined by the quality of the tie between each individual and the 
network as a whole (indicating feelings such as generalized trust, identification with the network and obligation to the network), rather than the quality of the ties between individuals.

\section{Relational strength of ties and social controls in electronic networks of practice}

In the absence of formal controls, such as contracts or hierarchical structures, networks rely on social controls to coordinate and influence the behavior of individuals in the network. Prior research indicates that social controls based on value consensus within a network may be more powerful, less apparent, and more difficult to resist than formal controls, constraining behavior even more effectively than formal contracts or hierarchical structures (Barker, 1993). However, in some networks, such as those where individuals are not physically in the presence of each other, social controls are not as likely to be dominating, thus allowing for more individual freedom in action (Teigland and Wasko, 2003). Networks improve their chances of success when they can offer social incentives consisting of rewards or benefits to an individual for participating (Olson, 1965). In electronic networks of practice, where contributions are visible to the network as a whole, one such positive social control is reputation and status within the network (Constant et al., 1996). Reputation is an important asset that an individual can leverage to achieve and maintain status within a collective (Jones et al., 1997). Reputation refers to others' perceptions of one's overall quality or character (Gemser and Wijnberg, 2001) and relays information about prior behaviors (Jones et al., 1997). Reputations are important for network coordination because they allow each network member to infer information about every other network member, regardless of prior personal interactions.

Networks are also able to leverage negative social controls to sanction misbehavior. Negative social controls are punishments enforced by network members on individuals who violate network norms, values, or goals. There are many types of negative social controls available to electronic networks of practice. These include "flaming", shunning, and expulsion from the network (Markus et al., 2000). Flaming is an exchange of inflammatory messages, and shunning consists of ignoring or ostracizing a member of the network. Possibly the most drastic negative social control for most network members is expulsion from the network on a temporary or permanent basis.

The effectiveness of social controls typically requires the recognition of individuals and their actions within the network. In face-to-face networks, the co-location of individuals serves to restrain behavior due to social stigma. However, due to the large size and relative anonymity of members in electronic networks of practice, it may be more difficult to monitor and reward interactions with social controls. In addition, the generalized nature of the exchange makes it more likely that individual interactions will go unnoticed by other network members. Therefore, we predict that the effectiveness of social controls in electronic networks of practice is more likely to be influenced by whether or not the overall network is important to members. When there is a high level of generalized trust, obligation, and identification with the network as a whole, then individuals are more likely to be influenced by social controls. This leads to the following proposition: 
Proposition 3: The higher the relational strength of the ties between individuals and the network as a whole, the greater the influence of social controls, such as reputation, status, flaming or shunning, on individual behavior.

\section{Relational strength of ties and knowledge contribution}

When networks are characterized by a high degree of trust, obligation, and identification between individuals and the network as a whole, individuals within the network are more likely to view their interests as aligned with those of the network's, leading to more positive interactions (Jones et al., 1997). Additionally, the identity of individual network members is more likely to matter, thus compelling members to engage with each other with at least some minimal level of courtesy and consideration (Williamson, 1991). Networks displaying characteristics of a high degree of trust, obligation, and identification have been found to facilitate knowledge exchange among scientists (Bouty, 2000), and build better employment practices (Leana and Van Buren, 1999).

Prior research in online settings indicates that trust in others' ability, benevolence, and integrity is related to a desire to both give and receive information (Ridings et al., 2002). Individuals with a strong sense of identification and attachment to electronic networks are more likely to participate and assist others (Wellman and Gulia 1997). There is also evidence that individuals posting valuable advice are motivated by a sense of obligation to the organization, or organizational citizenship (Constant et al., 1996), and that individuals are more likely to help others when they feel a sense of identification with the network and the network's goals (Lakhani and von Hippel, 2000). Therefore, we hypothesize that when an individual has a high degree of trust, obligation, and identification with the network as a whole, then he or she is more likely to help other members, regardless of personal acquaintance, status similarity, or expectations of reciprocity. Extrapolating this idea to the network level, we posit the following:

Proposition 4: The higher the relational strength of the ties between individuals and the network as a whole, the greater the overall level of knowledge contribution to the network.

\section{Social controls and knowledge contribution}

Social controls enhance cooperation and reduce misbehavior among network members by influencing the perceived costs of individual interactions. For example, network members enjoy recognition and fear being ostracized by their peers (Olson, 1965). Network members who are supportive of network goals and engage in positive interactions gain reputation and status in the network. On the other hand, members who engage in self-interested behaviors at the expense of the network incur the social wrath of others and risk being excluded from future exchanges (Ostrom, 1990). Social controls, such as reputation and status, encourage cooperation and helpful behaviors because individuals care about how they are perceived by others in the network, increasing the likelihood that individuals will forego acts of self-interest such as freeriding on the efforts of others (Markus et al., 2000).

In electronic networks of practice, social controls encourage the contribution of knowledge to the network. Results from prior research in electronic settings provides evidence that building one's reputation is a strong motivator for active participation (Donath, 1999) and for helping others (Constant et al., 1996; Rheingold, 1993), as well as a major reason why electronic networks are successful (Markus et al., 2000). We 
expect that network members would rather enjoy positive recognition from their peers than be ostracized or flamed. Thus, we predict that electronic networks of practice that effectively encourage social controls will have higher levels of knowledge contribution to the network. This leads to the following proposition:

Proposition 5: The greater the influence of social controls on individual behavior, the greater the overall level of knowledge contribution to the network.

\section{Distribution of individual motivations and resources and knowledge contribution}

In addition to the structure and relational strength of ties in the network, the distribution of individual motivations and resources in the network affects knowledge contribution in electronic networks of practice. In most volunteer networks, individuals have differing levels of interest in helping others as well as differing motives for participating, which in turn affects their levels of contribution (Marwell and Oliver, 1988). Hardin (1982) argued that individuals with high interest levels are those who lack private alternatives. In an electronic network of practice, this suggests that individuals who do not have access to knowledge and advice through their personal, private networks will be more likely to participate and share knowledge with strangers. There is some evidence from prior research that supports this suggestion. More specifically, individuals who did not have access to co-located colleagues were more likely to actively participate in an electronic network of practice (Wasko and Teigland, 2002). Prior research in electronic networks of practice also indicates that individual motivations such as organizational/community affiliation, access to a peer group and useful information, enjoyment, and learning influence participation in electronic networks (Constant et al., 1996; Lakhani and von Hippel, 2000; Wasko and Faraj, 2000).

In addition to motivations, the distribution of individual resources is also important (Hardin, 1982). For networks focused on creating and maintaining a public good, individuals within the network must have access to the required resources. These resources generally include money, time, expertise, energy, and influence (Oliver et al., 1985). In electronic networks of practice, prior research has found that people who have higher levels of professional expertise and organizational tenure are more likely to provide useful advice on computer networks (Constant et al., 1996). Other resources might include time, access to technology, or position in the shared practice.

These individual motivations and resources of an electronic network of practice may be distributed throughout the network. As discussed above, individuals voluntarily and individually determine how they want to participate and what they want to contribute, thus choosing what knowledge they are willing to disclose as well as the length of the messages they contribute. These decisions influence the quality and helpfulness of the knowledge exchanged. Thus, we predict that the distribution of individual motivations and resources within an electronic network of practice will influence knowledge contribution, where networks that have individuals with more resources and higher levels of motivation will generate greater knowledge contribution. This leads to the following proposition:

Proposition 6: The higher the individual motivations and resources in the electronic network of practice, the greater the overall level of knowledge contribution to the network. 


\section{Feedback from knowledge contribution to individual motivations and resources}

Networks that generate value through knowledge contribution are more likely to be sustained over time because they motivate members to continue participating (Jones et al., 1997; Krackhardt, 1992). Networks that generate value are also more likely to attract new members (Butler, 2001). These new members infuse additional resources to the network, which may lead to even more knowledge contribution and value creation over time. Thus, networks that generate value through productive exchanges are more likely to attract new resources, as well as strengthen the motivations of network members to continue participation, ensuring the sustainability of the network (Marwell and Oliver, 1988).

Therefore, we predict that in electronic networks of practice, the value created from contributing knowledge will affect the level of collective individual motivations and resources available to the network. Electronic networks of practice that generate knowledge that is valuable to network members should be able to attract additional resources (Butler, 2001). When individuals post messages that generate a valuable exchange of knowledge, they are more likely to be motivated to post additional messages containing relevant knowledge. This positive feedback between knowledge contribution and individual motivations and resources helps ensure that valuable knowledge contribution continues, influencing the sustainability of the network over time. This leads to the following proposition:

Proposition 7: The more knowledge contributed, the greater the overall level of individual motivations and resources available to the network.

\section{Feedback from knowledge contribution to the structure of network ties}

The contribution of knowledge to the network will also affect the structure of ties since the patterns of exchange that generate knowledge in the network also serve to recreate the network structure. This sequence of exchanges reflects a dynamic process of network organizing. The structural content of the message postings identifies the individuals engaged in the dyadic exchange, creating the new network structure and orders the messages so that the knowledge content and relational content make sense. Without the structural content, the messages would appear as random events, losing much of their relevance. Therefore, we expect that the relational characteristics and social controls, although developed through message content, only gain their relevance within the context of the network structure. Thus, the relational strength of ties and social controls can change over time, but these changes remain dependent upon network structure.

This dynamic process enables the network to change over time, reflecting the new pattern of relationships that develop. We have predicted that, due to the macrostructural properties underlying electronic networks of practice, the relationships that develop are knowledge-based rather than the result of personal acquaintance and reciprocity. However, the pattern of interactions that generate knowledge contribution may also create relationships based on personal familiarity, acquaintance, or even strong friendships between network members. To the extent that the collective action 
underlying knowledge contribution remains knowledge-based, we expect the pattern of knowledge contributions creating the network structure to remain generalized.

Proposition 8: The more knowledge contributed based on interest rather than personal acquaintance, the more the overall structure of ties will be characterized by generalized exchange.

\section{Discussion}

In this paper, we make a theoretical contribution to the general understanding of the social and organizational processes sustaining electronic networks of practice. Using theories of collective action and social networks, we propose possible answers to the question of how electronic networks of practice are sustained despite the lack of formal controls and the ability to free-ride on the efforts of others. We identify the important macrostructural properties of networks of practice that influence the structure and relational strength of ties in electronic networks of practice. Specifically, the model explains how the structure of ties affects the relational strength of ties. The relational strength of ties affects the extent to which social controls influence individual behavior, and both affect knowledge contribution in electronic networks of practice.

The dynamic aspect of the model explains how the patterns of interactions change over time, influencing the structure and relational strength of the network ties and the ability to attract and/or maintain resources. For instance, an electronic network of practice may begin through the efforts of a small number of individuals with direct and dense ties, which fuels initial knowledge contribution. As the membership of the network increases, the network structure changes, moving toward a more generalized pattern of exchange, which then leads to ongoing contribution and maintenance of the public good. ${ }^{1}$ An interesting area of further research would be to examine how the structure and relational strength of ties change over time and the implications for knowledge contribution.

Our collective action frame complements Butler's dynamic model (2001) based on size and communication; but our propositions provide an alternative explanation to the resource-based model Butler offers to explain the sustenance of online social structures. By focusing on the role of social networks, we are able to extend his findings by offering a fuller explanation as to the source of the resources that are provided online and how relational aspects underpin network dynamics. Our model also offers a generalization to Ahuja et al.'s (2003) finding that performance in virtual groups was driven by roles and centrality in the network. We support their findings regarding the importance of group structure for individual performance and extend their work by identifying group level relational factors that support network performance.

An interesting challenge in researching social networks is accurately identifying the macrostructural properties of the network of practice and how these may impact the structure and relational strength of ties in the network. For instance, some networks may incorporate formal controls to augment social controls. In electronic networks of practice, one potential formal control is restricting access to the network. This influences not only network size, access and the availability of potential resources, but may also influence the structural characteristics to the extent that the relationships become based

\footnotetext{
${ }^{1}$ We thank an anonymous reviewer for this insight.
} 
more on personal acquaintance than knowledge. Another case would be an electronic network of practice supporting a physical entity, or to support additional interactions within a wider network of practice. Research that examines networks with both physical and electronic communications needs to consider the additional influence of the relations that develop between individuals and the physical network, as well as the electronic network (Constant et al., 1996).

Another interesting case is when a formal organization provides tangible incentives to encourage participation in an electronic network of practice. Gu and Jarvenpaa (2003) found that organizations are using incentive schemes that enhance an individual's reputation by creating individualized profiles for participants. Dell and Hewlett Packard use incentives based on status through the categorization of users by their participation, and Hewlett Packard offers an additional incentive designed to enhance competition and continued use by providing a list of the top users (Gu and Jarvenpaa, 2003). Tangible incentives have also been used. For instance, Microsoft offers their user group leaders access to "the latest technical education, content, and offerings covering Microsoft products and technologies" (http://msdn.microsoft.com/usergroups/). However, prior research on knowledge management systems suggests that the use of formal incentives to promote participation and knowledge contribution may actually be detrimental to the sustainability of electronic networks of practice (Gallivan et al., 2003). This use of formal controls on network structures is an area ripe for further investigation.

While we focus on the underlying factors that are likely to render sustainable, valuable knowledge contribution, the model may also be useful for explaining unproductive exchanges, or the contribution of knowledge that has little value. For example, we would expect that networks that do not leverage the importance of personal reputations by identifying network members or that do not punish misbehaviors are less likely to sustain contributions valued by network members. We would also expect that electronic networks of practice that produce less valuable knowledge will lose membership over time. This reduction in value results not only from too little contribution, but possibly from too much knowledge being contributed, making it difficult for network members to filter through messages in search of the ones relevant for them (Butler, 2001).

Our model is not without limitations. Our collective action perspective operates at the network level and does not offer much explanation as to why certain individuals take on specific roles or participate the way that they do. While previous research has found that higher levels of participation in electronic networks of practice positively impact an individual's performance within the firm (Teigland and Wasko, 2003), we know little about the minimum number of individuals nor the distribution of motivations and resources at the network level necessary to maintain the network. For instance, we suspect that collective action may be relatively easier to sustain in electronic networks of practice since the creation of the public good does not require the coordinated efforts of all or even a majority of individuals in the network. There is some evidence to support this position from prior research, which indicates that in addition to generalized exchange, the structure of ties shows a fairly high degree of centralization, where the majority of messages is contributed by a few very active members (Wasko and Teigland, 2002). Thus, investigation of individual roles, the distribution of motivations and resources in the network, and how these affect network structure are all areas in need of further research. 
A related limitation of our theory is that we have not investigated the impact of negative participation and what this would consist of, beyond suggesting that this type of participation creates less value. Further research that focuses on the resilience of electronic networks of practice in the face of adversity, such as high levels of spam; the effects of rapid changes in membership; and the adaptability of the network to changes in the environment is also needed.

Another boundary condition for our model is the development of social ties over time. In our conceptualization, because the electronic network of practice is large and consists primarily of dispersed individuals, it was reasonable to make a basic assumption of generalized exchange between strangers. However, as many participants in online groups attest (Preece, 2002; Rheingold, 1993), frequent participants may develop direct ties based on email exchanges outside the scope of the electronic network of practice or meet face-to-face in other settings. Thus, when a significant number of network members no longer engage in generalized exchange and focus on reciprocal exchanges with select others, the network structure changes, and the electronic network of practice may become a closed group unwelcoming to newcomers.

In conclusion, we have offered a model of online collective action that explains how knowledge contributions are sustained in electronic networks of practice. Much research remains to be done to understand individual behaviors and how the different macrostructural properties of networks generate different dynamics. By defining constructs and developing clear propositions, we have offered an agenda for future research. Moreover, we suggest that the framework provided here is an early step in understanding electronic networks of practice and the dynamics of these new organizational forms based on networks of volunteers enabled by computer-mediated communication.

\section{References:}

Ahuja, M., D. Galletta, and K. Carley (2003) "Individual Centrality and Performance in Virtual R\&D Groups: An Empirical Study," Management Science (49:1) 2003, pp. 21-38.

Allen, T.J. (1977) Managing the Flow of Technology, Cambridge, MA: MIT Press.

Barker, J.R. (1993) "Tightening the Iron Cage: Concertive Control in Self-Managing Teams", Administrative Science Quarterly, (38), pp. 408-437.

Blau, P.M.(1964) Exchange and Power in Social Life, New York, NY: Wiley.

Bourdieu, P. (1977) Outline of a Theory of Practice, New York, NY: Cambridge University Press.

Bouty, I. (2000) "Interpersonal and Interaction Influences on Informal Resource Exchanges between R\&D Researchers across Organizational Boundaries", Academy of Management Journal, (43)1, pp. 50-66.

Brown, J.S., and P. Duguid (1991) "Organizational Learning and Communities-ofPractice: Toward a Unified View of Working, Learning, and Innovation", Organization Science, (2)1, pp. 40-57.

Brown, J.S., and P. Duguid (2000) The Social Life of Information, Boston, MA: Harvard Business School Press.

Brown, J.S., and P. Duguid (2001) "Knowledge and Organization: A Social-Practice Perspective", Organization Science, (12)2, pp.198-213. 
Butler, B.S. (2001) "Membership Size, Communication Activity, and Sustainablility: A Resource-Based Model of Online Social Structures", Information Systems Research, (12)4, pp. 346-362.

Cohen, B.P., and X. Zhou (1991) "Status Processes in Enduring Work Groups", American Sociological Review, (56), pp. 179-188.

Coleman, J.S. (1990) Foundations of Social Theory, Cambridge, MA: Belknap Press of Harvard University Press.

Constant, D., L. Sproull, and S. Kiesler. (1996) "The Kindness of Strangers: The Usefulness of Electronic Weak Ties for Technical Advice", Organization Science, (7)2, pp. 119-135.

Daft, R.L., and R. H. Lengel (1986) "Organizational Information Requirements, Media Richness and Structural Design", Management Science (32)5, pp. 355-366.

Donath, J.S. (1999) "Identity and Deception in the Virtual Community", in: M. A. Smith and P. Kollock (eds.) (1999) Communities in Cyberspace, New York, NY: Routledge, pp. 29-59.

Ekeh, P.P. (1974) Social Exchange Theory: The Two Traditions Cambridge, MA: Harvard University Press.

Friedkin, N. (1982) "Information Flow through Strong and Weak Ties in Intraorganizational Social Networks", Social Networks, (3), pp 273-285.

Fulk, J., A. J. Flanagin, M. E. Kalman, P. R. Monge, and T. Ryan (1996) "Connective and Communal Public Goods in Interactive Communication Systems", Communication Theory (6)1, pp. 60-87.

Gallivan, M.J., J. Eynon, and A. Rai (2003) "The Challenge of Knowledge Management Systems: Analyzing the Dynamic Processes Underlying Performance Improvement Initiatives", Information Technology and People (16)3, pp. 326-352.

Garton, L., C. Haythornthwaite, and B. Wellman (1999) "Studying on-Line Social Networks", in S. Jones (ed.) (1999) Doing Internet Research : Critical Issues and Methods for Examining the Net, Thousand Oaks, CA: Sage, pp. 75-105.

Gemser, G., and N. Wijnberg (2001) "Effects of Reputational Sanctions on the Competitive Imitation of Design Innovations", Organization Studies, (22)4, pp. 563-591.

Granovetter, M. (1985) "Economic Action and Social Structure: The Problem of Embeddedness", American Journal of Sociology, (91), pp. 481-510.

Granovetter, M.S. (1973) "The Strength of Weak Ties", American Journal of Sociology, (91), pp. 481-510.

Granovetter, M.S. (1992) "Problems of Explanation in Economic Sociology", in N. Nohria and R. Eccles (eds.) (1992) Networks and Organizations: Structure, Form and Action, Boston, MA: Harvard Business School Press, pp. 25-56.

Gu, B., and S. Jarvenpaa (2003) "Online Discussion Boards for Technical Support: The Effect of Token Recognition on Customer Contributions", Twenty-Fourth International Conference on Information Systems, Seattle, WA.

Hardin, R. (1982) Collective Action, Baltimore, MD: Johns Hopkins University Press.

Hinds, P., and S. Kiesler (2002) Distributed Work, Cambridge, MA: MIT Press, pp. 495.

Jones, C., W. S. Hesterly, and S. P. Borgatti (1997) "A General Theory of Network Governance: Exchange Conditions and Social Mechanisms", Academy of Management Review, (22)4, pp. 911-945.

Kollock, P., and M. A. Smith (1996) "Managing the Virtual Commons: Cooperation and Conflict in Computer Communities", in S. Herring (ed.) (1996) ComputerMediated Communication: Linguistic, Social and Cross Cultural Perspectives, Amsterdam: John Benjamins, pp. 109-128. 
Krackhardt, D. (1992) "The Strength of Strong Ties: The Importance of Philos in Organizations", in N. Nohria and R. Eccles (eds.) (1992) Organizations and Networks: Structure, Form, and Action, Boston, MA: Harvard Business School Press, pp. 216-239.

Kramer, R.M., M. B. Brewer, and B. Hanna (1996) "Collective Trust and Collective Action: The Decision to Trust as a Social Decision", in R. M. Kramer and T. R. Tyler (eds.) (1996) Trust in Organizations. Frontiers of Theory and Research, Thousand Oaks, CA: Sage, pp. 357-389.

Kraut, R.E., Egido, C., and J. Galagher (1990) "Patterns of Contact and Communication in Scientific Research Collaboration", in J. Galagher, R. E. Kraut, and C. Egido (eds.) (1990) Intellectual Teamwork, Hillsdale, NJ: Lawrence Erlbaum Associates.

Lakhani, K., and E. von Hippel (2000) "How Open Source Software Works: "Free" Userto-User Assistance", The 3rd Intangibles Conference. Knowledge: Management, Measurement and Organization, Stern School of Business, NYU.

Lave, J., and E. Wenger (1991) Situated Learning. Legitimate Peripheral Participation Cambridge, UK: Cambridge University Press.

Leana, C.R., and H. J. Van Buren (1999) "Organizational Social Capital and Employment Practices", The Academy Management Review, (24)3, pp. 538-555.

Lewicki, R.J., and B. B. Bunker (1996) "Developing and Maintaining Trust in Work Relationships", in R. M. Kramer and T. R. Tyler (eds.) (1996) Trust in Organizations, London: Sage Publications.

Markus, M.L., B. Manville, and C. E. Agres (2000) "What Makes a Virtual Organization Work?" Sloan Management Review, (42)1, pp. 13-26.

Marwell, G., and P. Oliver (1988) "Social Networks and Collective Action: A Theory of the Critical Mass III", American Journal of Sociology, (94)3, pp. 502-534.

McAllister, D. (1995) "Affect- and Cognition-Based Trust as Foundations for Interpersonal Cooperation in Organizations", Academy of Management Journal, (38)1, pp. 24-59.

Mowday, R.T., R. M. Steers, and L. Porter (1979) "The Measurement of Organizational Commitment", Journal of Vocational Behavior, (14), pp. 224-247.

Nahapiet, J., and S. Ghoshal (1998) "Social Capital, Intellectual Capital, and the Organizational Advantage", Academy of Management Review, (23)2, pp. 242266.

Oliver, P.E., G. Marwell, and R. Teixeira (1985) "A Theory of Critical Mass I: Group Heterogeneity, Interdependence and the Production of Collective Goods", American Journal of Sociology, (91), pp. 522-556.

Olson, M. (1965) The Logic of Collective Action, Cambridge, MA: Harvard University Press.

Organ, D.E. (1988) Organizaitonal Citizenship Behavior, Lexington, MA: Lexington Publishers.

Ostrom, E. (1990) Governing the Commons: The Evolution of Institutions for Collective Action, Cambridge: Cambridge University Press.

Pelled, L. H. (1996) "Demographic Diversity, Conflict, and Work Group Outcomes: An Intervening Process Theory", Organization Science, (7), pp. 615-631.

Preece, J. (2002) "Supporting Community and Building Social Capital", Communications of the ACM, (45)4, pp. 37-39.

Putnam, R.D. (2000) Bowling Alone, New York, NY: Simon \& Schuster.

Rheingold, H. (1993) The Virtual Community: Homesteading on the Electronic Frontier, Reading, MA: Addison Wesley. 
Ridings, C.M., Gefen, D., and B. Arinze (2002) "Some Antecedents and Effects of Trust in Virtual Communities", Journal of Strategic Information Systems, (11), pp. 271295.

Ring, P. S., and A. H. Van de Ven (1994) "Developmental Processes of Cooperative Interorganizational Relationships", Academy of Management Review, (19), pp. 90-118.

Samuelson, P. A. (1954) "The Pure Theory of Public Expenditure", Review of Economics and Statistics, (36), pp. 387-390.

Teigland, R., and M. Wasko (2003) "Integrating Knowledge through Information Trading: Examining the Relationship between Boundary Spanning Communication and Individual Performance", Decision Sciences, (34)2, pp. 261-286.

Wasko, M. and S. Faraj (2000) "It Is What One Does: Why People Participate and Help Others in Electronic Communities of Practice", Journal of Strategic Information Systems, (9)2-3, pp. 155-173.

Wasko, M., and R. Teigland (2002) "The Provision of Online Public Goods: Examining Social Structure in a Network of Practice", The 23rd Annual International Conference on Information Systems, Barcelona, Spain.

Wellman, B., and M. Gulia (1997) "Net Surfers Don't Ride Alone", in P. Kollock and P. Smith (eds.) (1997) Communities in Cyberspace, Berkeley, CA: University of California Press.

Wenger, E. (1998) Communities of Practice, Cambridge, UK: Cambridge University Press, pp. 318.

Williamson, O.E. (1991) "Comparative Economic Organization: The Analysis of Discrete Structural Alternatives", Administrative Science Quarterly, (36), pp. 269-296.

\section{Acknowledgements}

We would like to thank the editors of the special issue, especially Bob Zmud, as well as our anonymous reviewers for their efforts in helping us develop this paper, and for an exemplary review process as a whole. Special thanks to Herbert R. McLure for his comments on earlier drafts of this work. We would also like to acknowledge the participation and feedback from our colleagues at the JAIS Theory Development Workshop, Seattle, 2003: Alok Chaturvedi, Arun Rai, Gerald Kane, Yuan Li, and William Kettinger and the extraordinary organizational skills of Geng Yang.

\section{About the authors}

Molly McLure Wasko is an assistant professor in the department of Management Information Systems at Florida State University where she teaches primarily strategic information technologies. She received her doctorate in MIS from the University of Maryland, College Park, and she holds an M.B.A. from Averett University. Prior to getting her doctorate, she spent eight years working in production and operations management. Her research interests include technology and strategy, the development of online knowledge communities, and the strategic human resource management of IT professionals. Her work has appeared in the Journal of Strategic IS and Decision Science, and has been presented at ICIS, AOM, and AMCIS. She is a member of the Academy of Management, AIS and INFORMS. 
Samer Faraj is an assistant professor in the Department of Decision and Information Technologies at the University of Maryland, College Park. He received his doctorate in MIS from Boston University's school of management and holds an M.S. in Technology and Policy from MIT. Prior to getting his doctorate, he spent a decade working in a variety of consulting and IS positions. His research interests include the coordination of expertise in knowledge teams in settings such as software development and trauma care, the development of online knowledge communities, and the impact of IT on organizations. His work has appeared in journals such as: Information Systems Research, Management Science, the Journal of Applied Psychology, the Journal of Strategic IS, and Information Technology \& People. He serves on the editorial review board of Organization Science and is an associate editor of Information Systems Research.

Robin Teigland is an Assistant Professor and a member of the core faculty of the new full-time MBA program at the Stockholm School of Economics (SSE). Robin's research interests include areas such as the creation and diffusion of knowledge in interorganizational networks of practice and the impact on a firm's competitive advantage. The focus of her current research is within the biotechnology industry in which she is investigating the relationship between social networks and performance at various levels. This research includes projects such as a study of the emergence of Sweden's stem cell industry and a study of the development of the Uppsala Biotech Cluster (together with CIND at Uppsala University, www.cind.se). Prior to completing her doctoral thesis at the Institute of International Business at SSE, Robin worked as a consultant for McKinsey \& Company, Inc. in Stockholm. Additionally, she holds a B.A. in Economics from Stanford University, an M.B.A. from The Wharton School, and an M.A. in International Studies from the University of Pennsylvania.

Copyright @ 2004 by the Association for Information Systems. Permission to make digital or hard copies of all or part of this work for personal or classroom use is granted without fee provided that copies are not made or distributed for profit or commercial advantage and that copies bear this notice and full citation on the first page. Copyright for components of this work owned by others than the Association for Information Systems must be honored. Abstracting with credit is permitted. To copy otherwise, to republish, to post on servers, or to redistribute to lists requires prior specific permission and/or fee. Request permission to publish from: AIS Administrative Office, PO Box 2712 Atlanta, GA, 30301-2712, Attn: Reprints, or via e-mail from ais@aisnet.org. 
EDITOR

Sirkka L. Jarvenpaa

University of Texas at Austin

JAIS SENIOR EDITORS

\begin{tabular}{|l|l|l|}
\hline $\begin{array}{l}\text { Soon Ang } \\
\text { Nanyang Technological University }\end{array}$ & $\begin{array}{l}\text { Izak Benbasat } \\
\text { University of British Columbia }\end{array}$ & $\begin{array}{l}\text { Matthias Jarke } \\
\text { Technical University of Aachen }\end{array}$ \\
\hline $\begin{array}{l}\text { Kalle Lyytinen } \\
\text { Case Western Reserve University }\end{array}$ & $\begin{array}{l}\text { Tridas Mukhopadhyay } \\
\text { Carnegie Mellon University }\end{array}$ & $\begin{array}{l}\text { Robert Zmud } \\
\text { University of Oklahoma }\end{array}$ \\
\hline
\end{tabular}

JAIS EDITORIAL BOARD

\begin{tabular}{|c|c|c|c|}
\hline $\begin{array}{l}\text { Ritu Agarwal } \\
\text { University of Maryland }\end{array}$ & $\begin{array}{l}\text { Paul Alpar } \\
\text { University of Marburg }\end{array}$ & $\begin{array}{l}\text { Anandhi S. Bharadwaj } \\
\text { Emory University }\end{array}$ & $\begin{array}{l}\text { Yolande E. Chan } \\
\text { Queen's University }\end{array}$ \\
\hline $\begin{array}{l}\text { Alok R. Chaturvedi } \\
\text { Purdue University }\end{array}$ & $\begin{array}{l}\text { Roger H.L. Chiang } \\
\text { University of Cincinnati }\end{array}$ & $\begin{array}{l}\text { Wynne Chin } \\
\text { University of Houston }\end{array}$ & $\begin{array}{l}\text { Ellen Christiaanse } \\
\text { University of Amsterdam }\end{array}$ \\
\hline $\begin{array}{l}\text { Alan Dennis } \\
\text { Indiana University }\end{array}$ & $\begin{array}{l}\text { Amitava Dutta } \\
\text { George Mason University }\end{array}$ & $\begin{array}{l}\text { Robert Fichman } \\
\text { Boston College }\end{array}$ & $\begin{array}{l}\text { Henrique Freitas } \\
\text { Universidade Federal do Rio } \\
\text { Grande do Sul }\end{array}$ \\
\hline $\begin{array}{l}\text { Guy G. Gable } \\
\text { Queensland University of } \\
\text { Technology }\end{array}$ & $\begin{array}{l}\text { Rudy Hirschheim } \\
\text { Louisiana State University }\end{array}$ & $\begin{array}{l}\text { Juhani Iivari } \\
\text { University of Oulu }\end{array}$ & $\begin{array}{l}\text { Matthew R. Jones } \\
\text { University of Cambridge }\end{array}$ \\
\hline $\begin{array}{l}\text { Elena Karahanna } \\
\text { University of Georgia }\end{array}$ & $\begin{array}{l}\text { Robert J. Kauffman } \\
\text { University of Minnesota }\end{array}$ & $\begin{array}{l}\text { Prabhudev Konana } \\
\text { University of Texas at } \\
\text { Austin }\end{array}$ & $\begin{array}{l}\text { Kai H. Lim } \\
\text { City University of Hong } \\
\text { Kong }\end{array}$ \\
\hline $\begin{array}{l}\text { Claudia Loebbecke } \\
\text { University of Cologne }\end{array}$ & $\begin{array}{l}\text { Mats Lundeberg } \\
\text { Stockholm School of Economics }\end{array}$ & $\begin{array}{l}\text { Stuart E. Madnick } \\
\text { Massachusetts Institute of } \\
\text { Technology }\end{array}$ & $\begin{array}{l}\text { Ann Majchrzak } \\
\text { University of Southern } \\
\text { California }\end{array}$ \\
\hline $\begin{array}{l}\text { Ryutaro Manabe } \\
\text { Bunkyo University }\end{array}$ & $\begin{array}{l}\text { Anne Massey } \\
\text { Indiana University }\end{array}$ & $\begin{array}{l}\text { Eric Monteiro } \\
\text { Norwegian University of } \\
\text { Science and Technology }\end{array}$ & $\begin{array}{l}\text { B. Jeffrey Parsons } \\
\text { Memorial University of } \\
\text { Newfoundland }\end{array}$ \\
\hline $\begin{array}{l}\text { Nava Pliskin } \\
\text { Ben-Gurion University of } \\
\text { the Negev }\end{array}$ & $\begin{array}{l}\text { Jan Pries-Heje } \\
\text { Copenhagen Business School }\end{array}$ & $\begin{array}{l}\text { Arun Rai } \\
\text { Georgia State University }\end{array}$ & $\begin{array}{l}\text { Sudha Ram } \\
\text { University of Arizona }\end{array}$ \\
\hline $\begin{array}{l}\text { Suzanne Rivard } \\
\text { Ecole des Hautes Etudes } \\
\text { Commerciales }\end{array}$ & $\begin{array}{l}\text { Rajiv Sabherwal } \\
\text { University of Missouri - St. Louis }\end{array}$ & $\begin{array}{l}\text { Christopher Sauer } \\
\text { Oxford University }\end{array}$ & $\begin{array}{l}\text { Peretz Shoval } \\
\text { Ben-Gurion University }\end{array}$ \\
\hline $\begin{array}{l}\text { Sandra A. Slaughter } \\
\text { Carnegie Mellon University }\end{array}$ & $\begin{array}{l}\text { Christina Soh } \\
\text { Nanyang Technological University }\end{array}$ & $\begin{array}{l}\text { Ananth Srinivasan } \\
\text { University of Auckland }\end{array}$ & $\begin{array}{l}\text { Kar Yan Tam } \\
\text { Hong Kong University of } \\
\text { Science and Technology }\end{array}$ \\
\hline $\begin{array}{l}\text { Bernard C.Y. Tan } \\
\text { National University of } \\
\text { Singapore }\end{array}$ & $\begin{array}{l}\text { Dov Te'eni } \\
\text { Bar-Ilan University }\end{array}$ & $\begin{array}{l}\text { Yair Wand } \\
\text { University of British } \\
\text { Columbia }\end{array}$ & $\begin{array}{l}\text { Richard T. Watson } \\
\text { University of Georgia }\end{array}$ \\
\hline $\begin{array}{l}\text { Gillian Yeo } \\
\text { Nanyang Business School }\end{array}$ & $\begin{array}{l}\text { Youngjin Yoo } \\
\text { Case Western Reserve University }\end{array}$ & & \\
\hline
\end{tabular}

\section{ADMINISTRATIVE PERSONNEL}

Eph McLean

AIS, Executive Director

Georgia State University
Samantha Spears

Subscriptions Manager

Georgia State University
Reagan Ramsower

Publisher, JAIS

Baylor University 